\title{
Do Patients Want to Listen to a Diagnosis of Dementia in Korea? Preferences on Disclosing a Diagnosis of Dementia and Discussing Advance Care Planning in Elderly Patients with Memory Concerns and Their Families
}

\author{
Joon Hyung Jung, ${ }^{1,2}$, Min Joo Kim¹, Soo-Hee Choi ${ }^{1,2}$, Na Young Han ${ }^{1}$, Jee Eun Park, ${ }^{1,2}$ \\ Hye Youn Park ${ }^{3}$, Ji Won Han ${ }^{3}$, Dong Young Lee ${ }^{1,2} \bowtie$, and Hye Yoon Park ${ }^{1 凶}$ \\ ${ }^{1}$ Department of Psychiatry, Seoul National University Hospital, Seoul, Republic of Korea \\ ${ }^{2}$ Department of Psychiatry, Seoul National University College of Medicine, Seoul, Republic of Korea \\ ${ }^{3}$ Department of Neuropsychiatry, Seoul National University Bundang Hospital, Seongnam, Republic of Korea
}

\begin{abstract}
Objective In this study, we aimed to investigate preferences regarding the disclosure of a dementia diagnosis and advance care planning (ACP) in patients with memory complaints and their families.

Methods A total of 98 patients who visited the department of psychiatry at a tertiary hospital with memory complaints and 62 family members completed a structured questionnaire. The questionnaire included preferences on disclosure of dementia and cancer diagnosis, awareness and preferences on ACP.

Results In total, $96.9 \%$ of patients were willing to know their dementia diagnosis. There were no significant differences in preferences between the diagnosis of cancer and dementia. Only $24.7 \%$ of patients and $45.8 \%$ of family members have heard of ACP. However, $82.8 \%$ of patients agreed on the necessity of ACP under the current condition. Multivariate analysis revealed that younger patients were more likely to agree with necessity for ACP under the current condition.

Conclusion In Korea, patients with memory complaints and their family members strongly favored a disclosure of dementia diagnosis. The majority of participants also agreed on the necessity of ACP. More active involvement of patients is needed in treatment decisions and care planning in cases of dementia as well as other life-threatening illnesses.

Psychiatry Investig 2017;14(6):779-785
\end{abstract}

Key Words Disclosure, Dementia, Advance care planning, Family, Surveys and questionnaires.

\section{INTRODUCTION}

Dementia is one of the most disabling disorders during the late-life period and affects millions of people around the world. The majority of dementia cases come from neurodegenera-

Received: March 29, 2017 Revised: June 14, 2017

Accepted: July 26, 2017 Available online: September 15, 2017

$\triangle$ Correspondence: Dong Young Lee, $\mathrm{MD}, \mathrm{PhD}$

Department of Psychiatry, Seoul National University Hospital, 101 Daehak-ro, Jongno-gu, Seoul 03080, Republic of Korea

Tel: +82-2-2072-2457, Fax: +82-2-744-7241, E-mail: selfpsy@snu.ac.kr

$\triangle$ Correspondence: Hye Yoon Park, MD, PhD

Department of Psychiatry, Seoul National University Hospital, 101 Daehak-ro, Jongno-gu, Seoul 03080, Republic of Korea

Tel: +82-2-2072-2457, Fax: +82-2-744-7241, E-mail: psychepark@gmail.com

(c) This is an Open Access article distributed under the terms of the Creative Commons Attribution Non-Commercial License (http://creativecommons.org/licenses/by$\mathrm{nc} / 4.0$ ) which permits unrestricted non-commercial use, distribution, and reproduction in any medium, provided the original work is properly cited. tive causes such as Alzheimer's disease, Lewy body dementia, or frontotemporal dementia. The cases progress until death despite current pharmacological treatment. As dementia progresses to a terminal state, the goal of treatment becomes palliative. ${ }^{1}$ However, approximately $40 \%$ of patients with advanced dementia receive invasive and burdensome interventions in the last three months of their life and receive suboptimal palliative care. ${ }^{2}$

In the terminal stage, patients' willingness to engage in a certain treatment is crucial in choosing a treatment option. ${ }^{3} \mathrm{Nev}$ ertheless, patients with dementia commonly lose their capacity to decide, and medical decisions at the terminal stage are usually made by family members. Therefore, it is difficult to respect patients' own values and preferences in this situation, and the responsibility for deciding becomes a significant burden on their caregivers. ${ }^{4,5}$ Advance care planning (ACP) is a pro- 
cess of decision making that promote patient participation in decisions about future care when he or she loses a capacity to decide. ${ }^{6}$ Discussing ACP in the early stage when a patient's decision capacity is preserved is important to ensure that his or her own view is reflected in medical decisions. ${ }^{78}$ This is particularly important in patients with dementia.

Disclosing a dementia diagnosis to a patient is the first step in beginning ACP and allowing patients to plan their life and treatments. Many patients with dementia do not know of their diagnosis, as the disclosure rate is reported to be less than $50 \%$, which is one of the lowest rates among life-threatening diseases. ${ }^{9,10}$ Previous studies have also indicated that health care providers were more likely to disclose a diagnosis to caregivers than patients themselves. ${ }^{9,10}$ How to deliver a dementia diagnosis to patients or their families has been controversial, and preferences for disclosure vary among studies and countries and have shifted over time. ${ }^{11}$ Moreover, only a few studies have been conducted in Asia on this issue. ${ }^{12-14}$ A Korean study conducted in 2005 reported that $51.3 \%$ of healthy elderly people and $58.9 \%$ of families with dementia patients wanted to hear a dementia diagnosis. ${ }^{14}$

In this study, we aimed to investigate the preferences on dementia disclosure and ACP in elderly outpatients with memory complaints and their families. Furthermore, we compared their attitudes for dementia diagnosis with those for cancer diagnosis, which is widely accepted to be disclosed to patients, although cancer is a life-threatening disease.

\section{METHODS}

\section{Participants}

We surveyed elderly patients with memory complaints and their family members who visited the psychiatric outpatient clinic of Seoul National University Hospital from June 2016 to August 2016. Patients needed to be older than 60 years, able to understand the purpose of the study and able to complete the questionnaire. Family members needed to be at least 19 years old to be enrolled in the study. Informed consent was obtained from participants, and the study was approved by the Institutional Review Board at Seoul National University Hospital.

\footnotetext{
Assessment

All participants were asked to complete the structured questionnaire. The questionnaire was developed to assess the preferences regarding diagnosis disclosure and ACP for this study. One researcher received questions and explained the questionnaire if needed. Patients and family members were asked to answer the questions separately without consulting each other. The surveillance took approximately 15-20 minutes and included the following: 1) preferences for disclosing a diagnosis
}

to self and to their family members in case of dementia (yes/ no); 2) preferences for disclosing a diagnosis in case of cancer (yes/no); 3) awareness on ACP or advance directives (yes/no/ don't know); 4) opinions on the necessity of ACP under the current condition and in certain hypothetical circumstances, including dementia, cancer, and terminal status, regardless of disease (yes/no/don't know); 5) preferences regarding life-sustaining treatments (cardiopulmonary resuscitation, mechanical ventilator, hemodialysis, vasopressors or antibiotics use, artificial nutrition, and artificial hydration) at terminal status (wish/do not wish/don't know/delegate a surrogate); 6) opinion on whom they want to appoint as a health care proxy; and 7) willingness to begin ACP now (5-point Likert scale). Clinical information, including clinical diagnosis, the Mini-Mental Status Examination (MMSE) score, and medication, was obtained from medical records.

\section{Statistical analysis}

All statistical analysis was performed using SPSS (version 21.0; IBM Corp., Armonk, NY, USA). The chi-square test, independent t-test, and Fisher's exact test were used for comparison of demographics between patients and family members, and preferences between dementia and cancer diagnosis.

We performed backward multiple logistic regression analyses to determine factors significantly associated with necessity for ACP under the current condition and at terminal dementia and willingness to write ACP now. We first ran univariate analyses and selected the factors with p-value less than 0.20 from the following variables: age, gender, presence of a spouse, education, income, religious affiliation or belief, presence of dementia or mild cognitive impairment, preferences on disclosure of dementia or cancer diagnosis and presence of a family member with dementia or cancer. With these selected variables, backward multiple logistic regression analyses were performed. All statistical tests were two-sided, and p-values $<0.05$ were considered significant.

\section{RESULTS}

\section{Characteristics of participants}

Of 105 patients who were referred, 103 patients and 68 family members agreed to participate in the study. Ninety-eight (93.3\%) patients and 62 (91.2\%) family members completed the questionnaire. Participants who did not complete the questionnaire were excluded. Characteristics of the participants are shown in Table 1 . The mean age of patients and family members was $75.0 \pm 5.0$ and $63.8 \pm 12.8$ years, respectively. The patient group was older $(\mathrm{p}<0.001)$, less educated $(\mathrm{p}=0.002)$, less married ( $\mathrm{p}=0.002)$, and had lower income $(\mathrm{p}=0.032)$ than the family group. Of the 98 patients, 52 were diagnosed with 
Table 1. Demographics and clinical characteristics of the participants

\begin{tabular}{|c|c|c|c|}
\hline & Patient $(\mathrm{N}=98)$ & Family $(\mathrm{N}=62)$ & p-value \\
\hline Age (yr, mean $\pm S D)$ & $75.0 \pm 5.0$ & $63.8 \pm 12.8$ & $<0.001^{* *}$ \\
\hline Gender, M/F (\%) & $33(33.7) / 65(66.3)$ & $26(41.9) / 36(58.1)$ & 0.291 \\
\hline \multicolumn{4}{|l|}{ Education (yr), N (\%) } \\
\hline$\leq$ Middle school & $48(49.0)$ & $15(24.2)$ & \multirow[t]{2}{*}{$0.002^{* *}$} \\
\hline High school or beyond & $50(51.0)$ & $47(75.8)$ & \\
\hline \multicolumn{4}{|l|}{ Marital status, N (\%) } \\
\hline Married & $66(67.3)$ & $55(88.7)$ & \multirow[t]{3}{*}{$0.002^{* *}$} \\
\hline Divorced & $29(29.6)$ & $3(4.8)$ & \\
\hline Widowed & $3(3.1)$ & $4(6.5)$ & \\
\hline \multicolumn{4}{|l|}{ Income (1 million won) } \\
\hline$<200$ & $38(40.9)$ & $15(24.2)$ & \multirow[t]{3}{*}{$0.032^{*}$} \\
\hline $200-400$ & $37(39.8)$ & $26(41.9)$ & \\
\hline$>400$ & $18(19.4)$ & $21(33.9)$ & \\
\hline \multicolumn{4}{|l|}{ Diagnosis, $\mathrm{N}(\%)^{\dagger}$} \\
\hline Dementia & $25(25.5)$ & & \\
\hline Mild cognitive impairment & $52(53.1)$ & & \\
\hline Mood disorder & $15(15.3)$ & & \\
\hline Others & $7(7.1)$ & & \\
\hline MMSE (mean $\pm \mathrm{SD})(\mathrm{N}=58)$ & $22.34 \pm 4.04$ & & \\
\hline \multicolumn{4}{|l|}{ Relation of families (\%) } \\
\hline Spouses & & $36(58.1)$ & \\
\hline Adult children or their spouses & & $23(37.1)$ & \\
\hline Relatives & & $2(3.2)$ & \\
\hline Others & & $1(1.6)$ & \\
\hline
\end{tabular}

${ }^{*} \mathrm{p}<0.05,{ }^{* *} \mathrm{p}<0.001,{ }^{\dagger}$ one patient was diagnosed with both mild cognitive impairment and mood disorder. MMSE: the Mini-Mental Status Examination scale

mild cognitive impairment, 25 with dementia, and 15 with mood disorder. Among the 62 family members, 36 were spouses of patients, 23 were offspring or spouses of offspring, and 2 were relatives other than an offspring or a spouse.

\section{Preferences on disclosing a diagnosis of dementia to self and family members}

Most of the patients and family members preferred to know their diagnosis when affected with hypothetical dementia (patients, 96.9\%; families, 98.4\%) (Figure 1). There was no significant difference between the two groups. They also wished to inform their family members of their dementia diagnosis (patients, 94.8\%; families, 96.8\%) (Figure 1). The reasons for answering "yes" to the questions are summarized in Table 2. The most frequent answer was "it is my right to know the diagnosis" (46.3\%) followed by "to plan my life" (44.2\%) in the patient group. For the family group, the most frequent one was "to choose a treatment option" (63.9\%) followed by "to plan their life" (62.3\%). For hypothetical cancer cases, preference rates were comparable with those for dementia for both groups. In total, $95.9 \%$ of the patient group and $100 \%$ of the family group wanted to be informed of a hypothetical cancer diagnosis.

The vast majority of each group also preferred to tell their families of their cancer diagnosis (patients, 92.8\%; families, 98.4\%). There was no group difference in either question. There was also no significant difference between cancer and dementia on disclosure preferences in either group.

\section{Attitudes toward ACP}

Only $24.5 \%$ of the patient group had ever heard of ACP, which was significantly lower than the family group (patients, $24.5 \%$; families, 45.2\%; $\mathrm{p}=0.007$ ) (Table 3). The majority of participants from both groups agreed on the necessity of ACP under the current condition and in hypothetical conditions including dementia (Figure 2). Although the family group showed a trend of higher agreement rate for the necessity of ACP than the patient group for all conditions, a statistically significant between- 
group difference was found only for the terminal stage, regardless of disease (patients, 74.5\%; families, 90.3\%; $\mathrm{p}=0.014$ ).

The willingness to begin ACP now was lower than the agreement rate on its necessity (Table 3 ). In total, $60 \%$ of the patient group and $77.4 \%$ of the family group either wished or strongly wished to initiate ACP now, and a stronger preference was observed in the family group ( $\mathrm{p}=0.023)$.

Multiple logistic regression analysis showed that younger age and positive attitude to disclosure of cancer diagnosis to families was associated with stronger needs for ACP under the current condition (Table 4). No factor was associated with the necessity for ACP at hypothetical dementia. Patients with a relative or a friend with dementia were more likely to either wish or strongly wish to begin ACP now $[\operatorname{Exp}(\beta)=0.274,95 \%$ CI $0.092-$

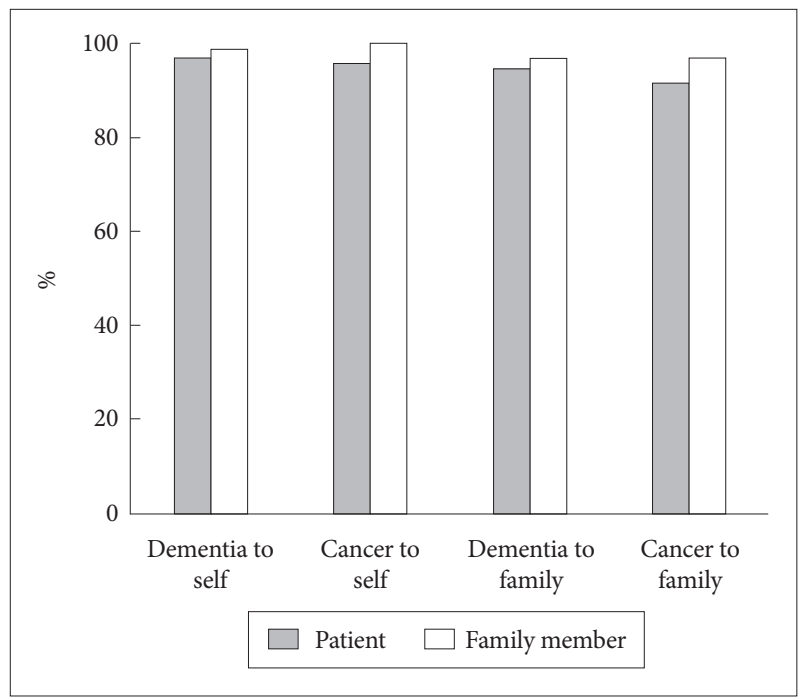

Figure 1. Preferences on disclosure of dementia and cancer diagnosis.
$0.819, \mathrm{p}=0.013]$.

\section{Preferences for health care proxy and life-sustaining treatment at terminal state}

Most patients and family members wanted their offspring or spouse to be their health care proxy (Table 3). Only a few participants stated that they do not need a health care proxy. More than half of both groups did not want life-sustaining treatment in the terminal state, and there was no group difference of "Do-Not-Wish" rates in all interventions (Figure 3).

\section{DISCUSSION}

The present study reveals that an overwhelming majority of patients visiting a hospital with memory complaints wish to know their diagnosis if they have dementia. The family group also strongly agreed with a disclosure of diagnosis, and preference rates were comparable with those in the case of a cancer diagnosis. These strong preferences were not affected by socioeconomic status (SES), age, or education level.

Compared to $51.3 \%$ of the elderly in the aforementioned survey in Korea in 2005, this study showed an enormous increase in the preference rate to disclose dementia. ${ }^{14}$ There can be several reasons, such as increased awareness of dementia among the general public as a decade passed in Korea ${ }^{15,16}$ and difference in the characteristics of participants. In our study, participants were patients who visited the tertiary hospital, while in previous study, community sample was studied. Patients' desire and right to know their medical status have increased recently. Following this change, recent studies reported higher favorable attitudes toward disclosure of life-threatening illness, including dementia, than studies in previous de-

Table 2. Reasons on disclosure of diagnosis to self and family

\begin{tabular}{|c|c|c|c|c|}
\hline & \multicolumn{2}{|c|}{ Patient $(\mathrm{N}=98)$} & \multicolumn{2}{|c|}{ Family $(\mathrm{N}=62)$} \\
\hline & Dementia & Cancer & Dementia & Cancer \\
\hline \multicolumn{5}{|l|}{ Reasons (disclosure to self) } \\
\hline It is my right to know the diagnosis & $44(46.3)$ & $46(48.9)$ & $22(36.1)$ & $46(74.2)$ \\
\hline To plan the life & $42(44.2)$ & $35(37.2)$ & $38(62.3)$ & $18(29.0)$ \\
\hline To understand the disease and my problem & $36(37.9)$ & $13(13.8)$ & $11(18.0)$ & $11(17.7)$ \\
\hline To find another doctor & $18(19.0)$ & $16(17.0)$ & $16(26.2)$ & $20(32.3)$ \\
\hline To choose treatment option & $32(33.7)$ & $40(42.6)$ & $39(63.9)$ & $43(69.4)$ \\
\hline To find resources for care & $18(19.0)$ & $13(13.8)$ & $19(31.1)$ & $15(24.2)$ \\
\hline \multicolumn{5}{|l|}{ Reasons (disclosure to families) } \\
\hline To plan the future with family members & $45(48.9)$ & $38(42.2)$ & $43(71.7)$ & $48(80.0)$ \\
\hline It is their right to know & $26(28.3)$ & $20(22.2)$ & $11(18.3)$ & $17(28.3)$ \\
\hline To family members to understand the disease & $34(37.0)$ & $37(41.1)$ & $26(43.3)$ & $21(35.0)$ \\
\hline To choose treatment option together & $50(54.3)$ & $49(54.4)$ & $38(63.3)$ & $39(65.0)$ \\
\hline To acquire resources and information about care & $25(27.2)$ & $16(17.8)$ & $14(23.3)$ & $14(23.3)$ \\
\hline
\end{tabular}


Table 3. Awareness and preferences on advance care planning

\begin{tabular}{|c|c|c|c|}
\hline & Patient $(\mathrm{N}=98)$ & Family $(\mathrm{N}=62)$ & $\mathrm{p}$-value \\
\hline \multicolumn{4}{|c|}{ I have heard about advance care planning } \\
\hline Yes & $24(24.7)$ & $28(45.2)$ & $0.007^{* *}$ \\
\hline No & $66(68.0)$ & $32(51.6)$ & \\
\hline I do not know & $7(7.2)$ & $2(3.2)$ & \\
\hline \multicolumn{4}{|l|}{ Health care proxy ${ }^{\dagger}$} \\
\hline Do not need & $6(6.1)$ & $3(4.8)$ & 0.869 \\
\hline Spouses & $45(45.9)$ & $30(48.4)$ & \\
\hline Offspring & $47(48.0)$ & $28(45.2)$ & \\
\hline Others & $5(5.1)$ & $5(8.1)$ & \\
\hline \multicolumn{4}{|c|}{ Wish to prepare advance care plan now } \\
\hline I strongly wish & $10(10.5)$ & $11(17.7)$ & $0.023^{*}$ \\
\hline I wish & $47(49.5)$ & $37(59.7)$ & \\
\hline Neutral & $13(13.7)$ & $8(12.9)$ & \\
\hline I do not wish & $25(26.3)$ & $6(9.7)$ & \\
\hline I strongly do not wish & $0(0)$ & $0(0)$ & \\
\hline
\end{tabular}

Either Chi-square test or Fisher's exact test was used. ${ }^{*} \mathrm{p}<0.05,{ }^{* *} \mathrm{p}<0.01,{ }^{\dagger} 3$ patients and 4 family members respond both spouse and adult child, 2 patients respond both adult child and others

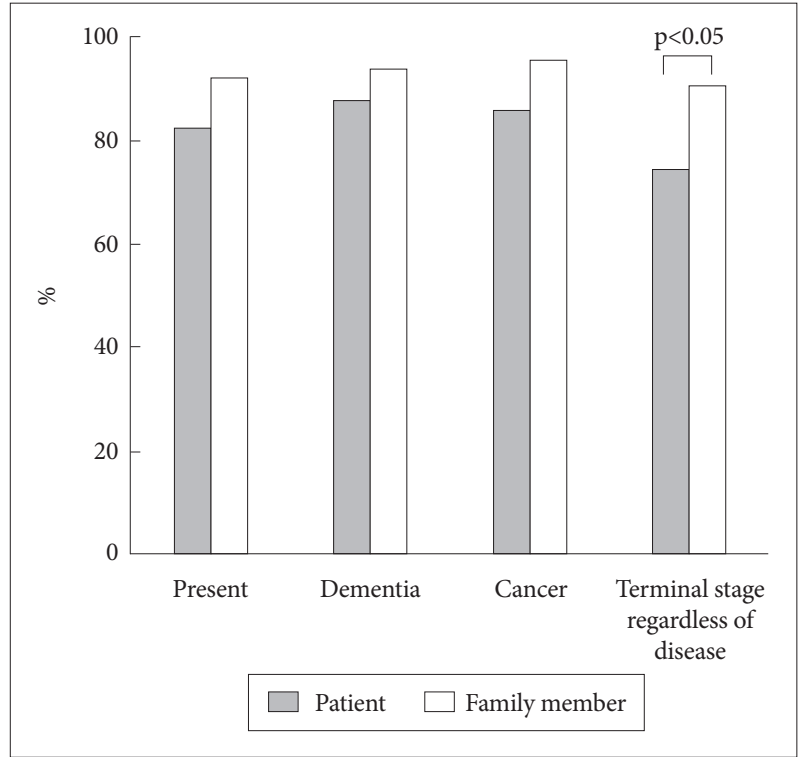

Figure 2. Agreements on necessity of advance care planning.

cades. $^{17-20}$

Rates of the favorable attitude toward disclosure of dementia in the study were higher than those in other studies surveying the general public. In Japan, 75.5\% of older respondents preferred to be informed, and a recent study from Italy reported that $83 \%$ of participants desired disclosure of diagnosis. ${ }^{12,21}$ The rates for wanting to know a diagnosis of dementia in this study were comparable to those in cancer from other studies, where $88 \%$ to $96 \%$ of patients want to know their cancer diagnosis. ${ }^{22-24}$ It is possible that participants would have a high- er interest in knowing if they have dementia specifically than other serious diseases such as cancer. The results from this study suggest that elderly people with memory concerns would be willing to listen to their diagnosis of dementia.

Awareness of ACP was lower than in studies from Western countries, where more than half of participants had some kind of advance planning. ${ }^{25,26}$ The family group was more likely to have heard of ACP and had a stronger wish to begin ACP now. This may be due to their younger age and higher education, given that age and education play an influential role in $\mathrm{ACP}^{27,28}$ Given that lack of knowledge and awareness of ACP in people with dementia are considered major barriers in conducting $\mathrm{ACP}^{29}$ efforts to raise public awareness of ACP are needed in Korea.

Participants felt less need for ACP at the hypothetical terminal state regardless of disease. People might feel that ACP was more necessary when assuming specific conditions rather than some distant hypothetical condition. This result indicates that when educating the general public on ACP, realizing the specific condition and situation can be more efficient. Having a family member or a close friend with dementia is associated with a stronger willingness to begin ACP now. This is consistent with previous studies that found having witnessed other people suffer from dementia facilitated initiation of $\mathrm{ACP} .^{30}$

There is no study that explores an actual disclosure rate of a dementia diagnosis by physicians in Korea. Studies from other countries revealed that less than half of the physicians disclosed the diagnosis of dementia., ${ }^{9,31}$ The rate is far less compared with other neurodegenerative diseases, such as Parkinson's 
Table 4. Multivariate analysis of factors associated with agreement with necessity on advance care planning

\begin{tabular}{|c|c|c|c|c|c|c|c|c|}
\hline & \multicolumn{4}{|c|}{ ACP under the current condition (yes) } & \multicolumn{4}{|c|}{ ACP at terminal dementia (yes) } \\
\hline & \multirow{2}{*}{ OR } & \multicolumn{2}{|c|}{$95 \% \mathrm{CI}$} & \multirow{2}{*}{ p-value } & \multirow{2}{*}{ OR } & \multicolumn{2}{|c|}{$95 \% \mathrm{CI}$} & \multirow{2}{*}{ p-value } \\
\hline & & Lower & Upper & & & Lower & Upper & \\
\hline \multicolumn{9}{|c|}{ Age, years } \\
\hline$<75$ & 7.17 & 1.46 & 35.24 & $0.015^{*}$ & 3.82 & 0.78 & 18.72 & 0.099 \\
\hline$\geq 75$ & 1.00 & & & & 1.00 & & & \\
\hline \multicolumn{9}{|c|}{ Disclosure of cancer diagnosis to a family member } \\
\hline Yes & 15.80 & 2.20 & 113.27 & $0.006^{* *}$ & & & & \\
\hline No & 1.00 & & & & & & & \\
\hline
\end{tabular}

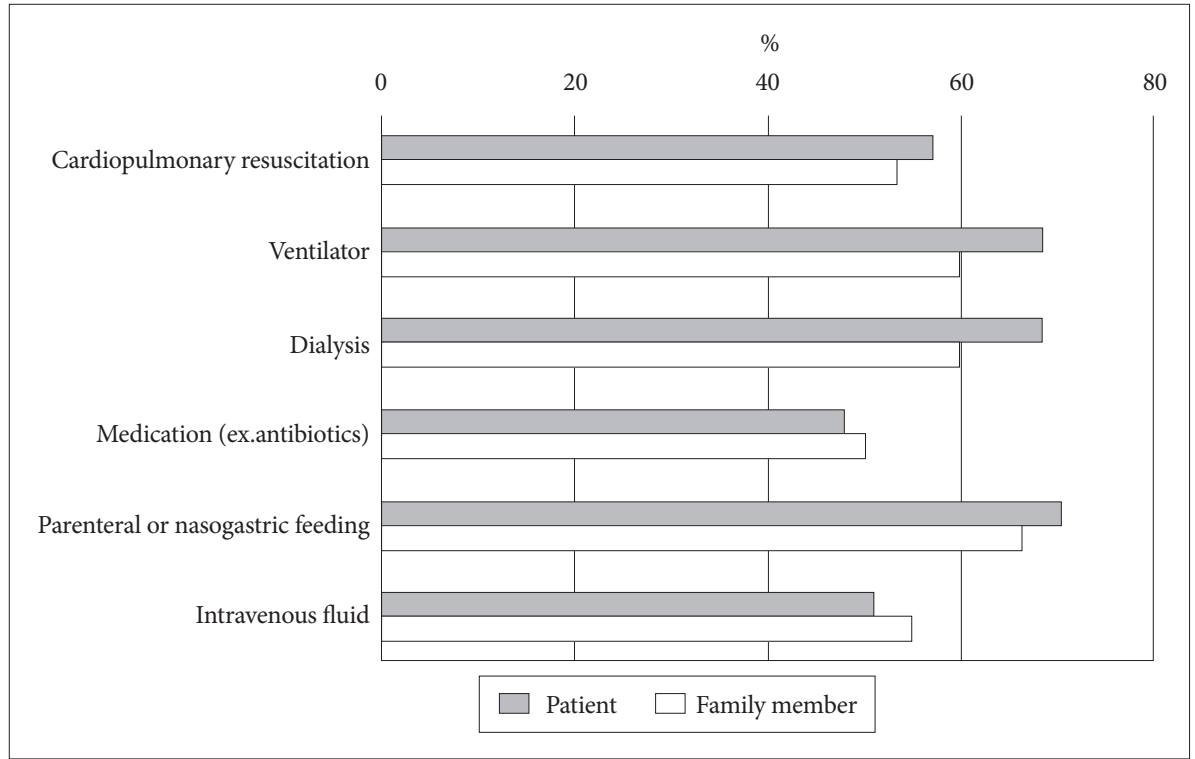

Figure 3. Rates of "Do-Not-Wish" on medical interventions at a terminal state. disease, which has a disclosure rate of $72 \% .^{9}$ Large discrepancies exist between patients' wishes and actual disclosure rates. For cancer, the trend was similar. In the 1960s, only a few physicians agreed to disclose cancer diagnoses, but this has dramatically changed because most people wanted to be informed, and the physicians' behavior shifted to more frequent disclosure. ${ }^{32,33}$ Currently, to tell cancer patients their diagnosis and prognosis has become routine practice. ${ }^{34-36}$ As a patients' right to know their medical status has been emphasized, it is likely that a dementia diagnosis would follow similar steps to narrow the gap between patients' wishes and actual practice.

Despite the high preference for disclosing a diagnosis of dementia, communication to break bad news should be conducted in a sensitive and considerate manner following a careful evaluation of the individual case. It was reported that some patients underwent extreme distress when they faced a diagnosis of dementia. ${ }^{37}$ Considering the potential impact on each patient, managing their fears about the future, and fostering their hope are needed in delivering a diagnosis of dementia. ${ }^{38,39}$
This study has several limitations. It was conducted at a single tertiary hospital in a large city with a relatively small sample size. While patients' accessibility to tertiary medical centers in Korea is fairly good, attitudes toward a disclosure of diagnosis or ACP can be varied according to regions or cultures. Therefore, multi-center, multi-region studies are needed to investigate patients' preferences and actual disclosure rates in Korea. Although small sample size limits interpretation in the general population, we approached people who are highly interested in dementia disclosure and with whom doctors could communicate about dementia in real practice.

The study has a practical value indicating that patients who actually visit a hospital with memory concerns would want to know a diagnosis of dementia. Physicians need to prepare for communication with patients in a more open manner. Further studies should address how to deliver a diagnosis and discuss care planning while minimizing possible negative psychological impacts, maximizing patients' hope and respecting their autonomy in each individual case. 


\section{Acknowledgments}

This study was supported by grant no. 04-2016-0660 from the SNUH research fund and a grant from the Ministry of Science, ICT and Future Planning (Grant No: NRF-2014M3C7A1046042).

\section{REFERENCES}

1. van der Steen JT, Radbruch L, Hertogh CM, de Boer ME, Hughes JC, Larkin P, et al. White paper defining optimal palliative care in older people with dementia: a Delphi study and recommendations from the European Association for Palliative Care. Palliat Med 2014;28:197-209.

2. Mitchell SL, Teno JM, Kiely DK, Shaffer ML, Jones RN, Prigerson HG, et al. The clinical course of advanced dementia. N Engl J Med 2009;361: 1529-1538.

3. Arcand M. End-of-life issues in advanced dementia: part 1: goals of care, decision-making process, and family education. Can Fam Physician 2015;61:330-334.

4. Shalowitz DI, Garrett-Mayer E, Wendler D. The accuracy of surrogate decision makers: a systematic review. Arch Intern Med 2006;166:493497.

5. Fetherstonhaugh D, McAuliffe L, Bauer M, Shanley C. Decision-making on behalf of people living with dementia: how do surrogate decisionmakers decide? J Med Ethics 2017;43:35-40.

6. Hayhoe B, Howe A. Advance care planning under the Mental Capacity Act 2005 in primary care. Br J Gen Pract 2011;61:e537-e541.

7. Poppe M, Burleigh S, Banerjee S. Qualitative Evaluation of Advanced Care Planning in Early Dementia (ACP-ED). PLoS One 2013;8:e60412.

8. de Boer ME, Dröes RM, Jonker C, Eefsting JA, Hertogh CMPM. Thoughts on the future: the perspectives of elderly people with earlystage alzheimer's disease and the implications for advance care planning. AJOB Prim Res 2012;3:14-22.

9. Alzheimer's Association. 2015 Alzheimer's disease facts and figures. Alzheimers Dement 2015;11:332-384.

10. van Hout HP, Vernooij-Dassen MJ, Jansen DA, Stalman WA. Do general practitioners disclose correct information to their patients suspected of dementia and their caregivers? A prospective observational study. Aging Ment Health 2006;10:151-155.

11. Bamford C, Lamont S, Eccles M, Robinson L, May C, Bond J. Disclosing a diagnosis of dementia: a systematic review. Int J Geriatr Psychiatry 2004;19:151-169.

12. Umegaki H, Onishi J, Suzuki Y, Endo H, Iguchi A. Attitudes toward disclosing the diagnosis of dementia in Japan. Int Psychogeriatr 2007;19: 253-265.

13. Lin KN, Liao YC, Wang PN, Liu HC. Family members favor disclosing the diagnosis of Alzheimer's disease. Int Psychogeriatr 2005;17:679-688.

14. Cheon JS, Kim IS, Oh BH, Cho W. Attitudes toward disclosing dementia diagnosis in Korean elderly and family with dementia patients. J Korean Geriatr Psychiatry 2005:112-121.

15. Ministry of Health and Welfare, 2012 The prevalence of dementia research., 2012. Available at http://download.mohw.go.kr/front_new/ modules/download.jsp?BOARD_ID=140\&CONT_SEQ=286138\& FILE_SEQ=134004. Accessed Feb 21, 2017.

16. Seoul Metropolitan Center for Dementia, 2015 Dementia Awareness Survey on Seoul Citizen., 2015. Available at http://www.seouldementia. or.kr/common/e-book_2015/20150925_1.pdf. Accessed Feb 21, 2017.

17. van den Dungen P, van Kuijk L, van Marwijk H, van der Wouden J, Moll van Charante E, van der Horst $\mathrm{H}$, et al. Preferences regarding disclosure of a diagnosis of dementia: a systematic review. Int Psychogeriatr 2014;26:1603-1618.

18. Jotkowitz A, Glick S, Gezundheit B. Truth-telling in a culturally diverse world. Cancer Invest 2006;24:786-789.

19. Horikawa N, Yamazaki T, Sagawa M, Nagata T. Changes in disclosure of information to cancer patients in a general hospital in Japan. Gen Hosp Psychiatry 2000;22:37-42.

20. Yun YH, Lee CG, Kim SY, Lee SW, Heo DS, Kim JS, et al. The attitudes of cancer patients and their families toward the disclosure of terminal illness. J Clin Oncol 2004;22:307-314.

21. Riva M, Caratozzolo S, Cerea E, Gottardi F, Zanetti M, Vicini Chilovi B, et al. Diagnosis disclosure and advance care planning in Alzheimer disease: opinions of a sample of Italian citizens. Aging Clin Exp Res 2014;26: 427-434.

22. Ajaj A, Singh MP, Abdulla AJ. Should elderly patients be told they have cancer? Questionnaire survey of older people. BMJ 2001;323:1160.

23. Meredith C, Symonds P, Webster L, Lamont D, Pyper E, Gillis CR, et al. Information needs of cancer patients in west Scotland: cross sectional survey of patients' views. BMJ 1996;313:724-726.

24. Chun IH, Park K. Patient's cognition toward the disclosure of cancer diagnosis. Asian Oncol Nurs 2013;13:59-66.

25. Lingler JH, Hirschman KB, Garand L, Dew MA, Becker JT, Schulz R, et al. Frequency and correlates of advance planning among cognitively impaired older adults. Am J Geriatr Psychiatry 2008;16:643-649.

26. Triplett P, Black BS, Phillips H, Fahrendorf SR, Schwartz J, Angelino AF, et al. Content of advance directives for individuals with advanced dementia. J Aging Health 2008;20:583-596.

27. Keam B, Yun YH, Heo DS, Park BW, Cho CH, Kim S, et al. The attitudes of Korean cancer patients, family caregivers, oncologists, and members of the general public toward advance directives. Support Care Cancer 2013;21:1437-1444.

28. Zhang N, Ning XH, Zhu ML, Liu XH, Li JB, Liu Q. Attitudes towards Advance Care Planning and Healthcare Autonomy among Community-Dwelling Older Adults in Beijing, China. Biomed Res Int 2015;2015: 453932.

29. Dickinson C, Bamford C, Exley C, Emmett C, Hughes J, Robinson L. Planning for tomorrow whilst living for today: the views of people with dementia and their families on advance care planning. Int Psychogeriatr 2013;25:2011-2021.

30. Hirschman KB, Kapo JM, Karlawish JH. Identifying the factors that facilitate or hinder advance planning by persons with dementia. Alzheimer Dis Assoc Disord 2008;22:293-298.

31. Clafferty RA, Brown KW, McCabe E. Under half of psychiatrists tell patients their diagnosis of Alzheimer's disease. BMJ 1998;317:603.

32. Oken D. What to tell cancer patients: a study of medical attitudes. JAMA 1961;175:1120-1128.

33. Novack DH, Plumer R, Smith RL, Ochitill H, Morrow GR, Bennett JM. Changes in physicians' attitudes toward telling the cancer patient. JAMA 1979;241:897-900.

34. Holland JC, Geary N, Marchini A, Tross S. An international survey of physician attitudes and practice in regard to revealing the diagnosis of cancer. Cancer Invest 1987;5:151-154.

35. Baile WF, Buckman R, Lenzi R, Glober G, Beale EA, Kudelka AP. SPIKESA six-step protocol for delivering bad news: application to the patient with cancer. Oncologist 2000;5:302-311.

36. Figg WD, Smith EK, Price DK, English BC, Thurman PW, Steinberg SM, et al. Disclosing a diagnosis of cancer: where and how does it occur? J Clin Oncol 2010;28:3630-3635.

37. Holroyd S, Turnbull Q, Wolf AM. What are patients and their families told about the diagnosis of dementia? Results of a family survey. Int J Geriatr Psychiatry 2002;17:218-221.

38. Mastwyk M, Ames D, Ellis KA, Chiu E, Dow B. Disclosing a dementia diagnosis: what do patients and family consider important? Int Psychogeriatr 2014;26:1263-1272.

39. Lee L, Weston WW. Disclosing a diagnosis of dementia: helping learners to break bad news. Can Fam Physician 2011;57:851-852, e270-e852. 